\title{
Efficacy Comparison of Preprandial and Postprandial Prandilin 25 Administration in Patients with Newly Diagnosed Type 2 Diabetes Using a Continuous Glucose Monitoring System
}

\author{
Yong Luo • Wen-ji Ni • BO Ding • Xiang-hong Xu • Lei Ye • \\ Jian-hua Ma $\cdot$ Jian Zhu iD
}

Received: October 31, 2018 / Published online: January 4, 2019

(C) The Author(s) 2019

\begin{abstract}
Introduction: The aim of this study was to determine the clinical efficacy of preprandial and postprandial Prandilin 25 (premixed insulin lispro 25) administration in patients with newly diagnosed type 2 diabetes mellitus (T2DM) using a continuous glucose monitoring (CGM) system.

Methods: This was a single-center, self-controlled comparative clinical trial. Newly diagnosed T2DM patients with hemoglobin A1c > 8.0\% were hospitalized and received Prandilin 25 plus metformin treatment. Glycemic control was reached after a 7-to-8-day run-in period. Patients underwent 2 days of treatment
\end{abstract}

Yong Luo and Wen-ji Ni equally contributed as first authors.

Enhanced Digital Features To view enhanced digital features for this article go to https://doi.org/10.6084/ m9.figshare.7381187.

Y. Luo · W. Ni · B. Ding $\cdot$ X. Xu · J. Ma $(\bowtie) \cdot J$. Zhu $(\bowtie)$

Department of Endocrinology, Nanjing First

Hospital, Nanjing Medical University, Nanjing,

China

e-mail:majianhua@china.comJ. Zhu

e-mail: drzhujian@hotmail.com

L. Ye

National Heart Research Institute Singapore,

National Heart Centre, Singapore, Singapore consisting of preprandial Prandilin 25 on day 1 and postprandial Prandilin 25 on day 2 at the same dosage. The primary outcome was the 24-h mean amplitude of glycemic excursion (24 hMAGE); secondary outcomes were other daily glycemic variability parameters, including 24-h mean blood glucose (24hMBG), 24-h standard deviation of blood glucose (24hSDBG), large amplitude of glycemic excursion (LAGE), incremental area under the curve (AUC) values for different glucose levels, postprandial glucose excursion, and incidence of hypoglycemia, which were assessed using a CGM system.

Results: Eighty-five patients completed this study. There was no statistically significant difference in 24hMAGE, 24hMBG, 24hSDBG, or LAGE between the preprandial injection group and the postprandial injection group. Similarly, there was no between-treatment difference in the AUC for a blood glucose level below $3.9 \mathrm{mmol} / \mathrm{L}$, in the AUC for a blood glucose level above $10.0 \mathrm{mmol} / \mathrm{L}$, or in the percentages of time that the blood glucose level was below $3.9 \mathrm{mmol} / \mathrm{L}$ or above $10.0 \mathrm{mmol} / \mathrm{L}$. Further analysis showed that the pre-meal glucose, peak height, and time to peak after each meal, the relative areas under the CGM curve at $1-4 \mathrm{~h}$ after each meal, as well as the incidence of hypoglycemia, were similar for the preprandial and postprandial Prandilin 25 groups.

Conclusion: In patients with T2DM managed with premixed insulin lispro 25, postprandial injection (within $30 \mathrm{~min}$ of meal onset) may be 
an acceptable alternative to preprandial injection when the regular preprandial insulin dose is omitted.

Trial Registration: Chinese Clinical Trial Register identifier: ChiCTR1800015828.

Keywords: Continuous glucose monitoring; Postprandial administration; Prandilin 25; T2DM

\section{INTRODUCTION}

The premixed insulin regimen is recommended and therefore widely used as the starter insulin in Asian patients due to their high carbohydrate consumption and/or early deterioration of $\beta$ cell function [1-3]. However, some large-scale studies have indicated that insulin omission/ nonadherence is common and associated with several modifiable risk factors, including regimen inflexibility, injection difficulties, and lifestyle burden [4-7]. Considering that premixed insulin analogues should usually be injected $5 \mathrm{~min}$ or immediately before meal onset $[8,9]$, identifying an acceptable meal-toinjection interval (MII) that provides injectiontime flexibility should theoretically increase the quality of life and therapy adherence of diabetic patients treated with premixed insulin analogues. Unfortunately, diabetes teaching and treatment programs and guidelines do not define an acceptable MII for patients who forget to inject premixed insulin analogues before a meal [1, 10, 11]; indeed, an appropriate or acceptable MII for type 2 diabetic patients managed with biphasic insulin analogues is yet to be defined due to a lack of relevant data. A few small-scale clinical studies [12-14] found that a 15-20 min MII did not significantly affect the glucose profiles of patients with type 2 diabetes mellitus (T2DM) managed with premixed insulin lispro 25 or Aspart 30 as compared to preprandial administration, based on self-monitoring of blood glucose and glycosylated hemoglobin A1c (HbA1c) changes. It should also be noted that most people take at least 30 min to finish a meal, especially in some social situations. In addition, premixed human insulin could be injected immediately before the start of the meal without compromising glucose control as compared to injection 20-30 min before meal onset [10, 15]. On the other hand, the peak action of premixed insulin analogues usually occurs 30-60 min earlier than the peak action of premixed human insulin $[8,16,17]$. We thus hypothesized that a MII of 30 min could be applied for the postprandial administration of premixed insulin analogues. Considering that Prandilin 25 (25\% insulin lispro, $75 \%$ neutral protamine lispro, made by Gan \& Lee Pharmaceuticals, China) is commonly used as low premixed insulin analogue in clinical practice in China, we performed the present study to investigate the difference in glucose profile between preprandial and postprandial Prandilin 25 administration in T2DM patients using a continuous glucose monitoring (CGM) system.

\section{METHODS}

\section{Subjects and Study Design}

This was a single-center, self-controlled comparative clinical trial (Chinese Clinical Trial Register identifier: ChiCTR1800015828). The study protocol was approved by the institutional ethical committee of Nanjing First Hospital, Nanjing Medical University. Informed consent was provided by all recruited subjects. All procedures followed were in accordance with the Helsinki Declaration of 1964, as revised in 2013.

Between May 2018 and September 2018, patients with T2DM were recruited as inpatients at the Department of Endocrinology, Nanjing First Hospital. The inclusion criteria were (1) antihyperglycemic drug-naive; (2) confirmed T2DM for at least 6 months; (3) HbA1c $\geq 8.0 \%$ at screening; (4) age between 18 and 80 years. The exclusion criteria were (1) serious acute and/or chronic complications, including ketoacidosis or a hyperosmolar state, severe cardiovascular diseases, end-stage renal disease; (2) severe infectious diseases on admission; (3) maturity-onset diabetes in the young, mitochondrial diabetes mellitus, or anti-glutamic acid decarboxylase antibody-positive; (3) known cancers; (4) pregnant or planning to 
become pregnant; (5) cognitive disorders, alcoholism, or drug abuse. After a physical examination and the collection of fasting blood samples, those patients were assigned Prandilin 25 (thrice a day, 5 min before meal onset) plus 1-1.5 g metformin per day. The insulin dose titration was performed as described in a previous study [18]. After a run-in period of 7-8 days, the capillary blood glucose levels of patients were maintained in the target range (preprandial glucose levels $\leq 7.8 \mathrm{mmol} / \mathrm{L}$ and 2 -h postprandial glucose levels $\leq 10.0 \mathrm{mmol} / \mathrm{L}$ ). The patients were then subjected to 2 days of treatment comprising standard preprandial Prandilin 25 (thrice a day, 5 min before meal onset) on day one and postprandial Prandilin 25 (30 min after meal onset) on day 2 at the same dosage. Patients were instructed to maintain the same eating times, food volumes, and physical activity during the CGM study period.

\section{CGM}

All patients consented to four consecutive days of CGM (Medtronic Inc., Northridge, CA, USA) by the specialist nurse in the hospital during the study period, as described in a previous study [18]. We analyzed the data collected during the CGM covering the periods (1) from $7 \mathrm{a} . \mathrm{m}$. on day 2 to 7 a.m. on day 3 (preprandial injection) and (2) from 7 a.m. on day 3 to 7 a.m. on day 4 (postprandial injection). The following parameters were calculated: mean amplitude of $24-\mathrm{h}$ mean blood glucose (24hMBG), glycemic excursion of blood glucose every $24 \mathrm{~h}$ (24hMAGE), standard deviation of 24-h blood glucose (24hSDBG), large amplitude of glycemic excursion (LAGE), area under the curve (AUC) for different glucose levels, and the time spent below $3.9 \mathrm{mmol} / \mathrm{L}$ or above $10.0 \mathrm{mmol} / \mathrm{L}$. The relative areas under the CGM curve (AUCpp) at 1-4 $\mathrm{h}$ after a meal were calculated as a measure of postprandial glucose excursions (PGE). The AUCpp was calculated as the glucose excursion relative to the baseline (pre-meal) value [19]. The postprandial glucose (PPG) peak was defined as the highest glucose value within a 3-h window from each meal start.

\section{Efficacy and Safety Assessments}

The primary outcome was 24hMAGE; the secondary outcomes were other daily GV parameters, including 24hMBG, 24hSDBG, LAGE, AUCs for and percentages of time spent at different glucose levels, PGE, and incidence of hypoglycemia. A severe hypoglycemic episode was defined as an event requiring the assistance of another person or resuscitative treatment. Minor hyperglycemia was defined as symptoms consistent with hypoglycemia (BG $<3.9 \mathrm{mmol} /$ L) that were handled by the patient himself/ herself or an asymptomatic BG measurement of $<3.9 \mathrm{mmol} / \mathrm{L}$.

\section{Statistical Analysis}

Data were analyzed with the SPSS PASW Statistics 19 package. Normally distributed and continuous variables are presented in this paper as the mean \pm standard deviation (SD). Non-normally distributed variables are given as median (interquartile range). The paired $t$ test or the Wilcoxon signed-rank test was performed to test between-group differences in GV and PGE. A multivariate general linear model (with treatment as a fixed effect) was used to compare hourly glucose concentrations between the two groups. The difference of hypoglycemia rate between the two groups were analyzed using the chi-square test. A $P$ value of $<0.05$ was considered to indicate statistical significance.

\section{RESULTS}

\section{Baseline Characteristics of the Patients}

Ninety-seven patients were enrolled in this clinical trial. Among those patients, five could not comply with the energy intake or physical activity instructions; three were unable to tolerate the $1 \mathrm{~g}$ /day dose of metformin, and four were excluded due to inadequate CGM data. Finally, 85 subjects $(87.63 \%)$ completed this study, and the mean total daily dose of Prandilin 25 was $0.42 \pm 0.16 \mathrm{U} / \mathrm{kg} /$ day (Table 1 ). 
Table 1 Baseline characteristics of the patients

\begin{tabular}{ll}
\hline Item & $n=85$ \\
\hline Gender (male/female) & $51 / 34$ \\
Age (years) & $56.28 \pm 10.91$ \\
BMI $\left(\mathrm{kg} / \mathrm{m}^{2}\right)$ & $24.72 \pm 2.97$ \\
HbAlc $(\%)$ & $10.62 \pm 1.50$ \\
FBG $(\mathrm{mmol} / \mathrm{L})$ & $11.83 \pm 2.70$ \\
Fasting insulin $(\mathrm{mIU} / \mathrm{L})$ & $6.62(4.26,9.54)$ \\
HOMA- $\beta$ & $16.99(9.79,26.00)$ \\
HOMA-IR & $2.92(2.21,5.83)$ \\
Insulin dosage $(\mathrm{U} / \mathrm{kg} / \mathrm{day})$ & $0.42 \pm 0.16$ \\
Diabetes retinopathy $(n / \%)$ & $1 / 1.18$ \\
Diabetes nephropathy $(n / \%)$ & $4 / 4.71$ \\
Hypertension $(n / \%)$ & $41 / 48.24$ \\
Hyperlipidemia $(n / \%)$ & $48 / 56.47$ \\
CAD $(\%)$ & $7 / 8.24$ \\
\hline
\end{tabular}

$B M I$ body mass index, $F B G$ fasting plasma glucose, HOMA- $\beta$ homeostasis model assessment of $\beta$-cell function, HOMA-IR homeostasis model assessment of insulin resistance, $C A D$ coronary atherosclerotic heart disease

\section{Efficacy Assessments}

There was no significant difference in 24hMAGE, 24hMBG, 24hSDBG, or LABG between the preprandial and postprandial administration groups. The AUCs of blood glucose below $3.9 \mathrm{mmol} / \mathrm{L}$ and above $10.0 \mathrm{mmol} / \mathrm{L}$ after postprandial Prandilin 25 injection were similar to those following preprandial Prandilin 25 injection. Similarly, there was no statistically significant difference between the treatments in the percentage of time that the blood glucose level was $<3.9 \mathrm{mmol} / \mathrm{L}$ or the percentage of time that blood glucose was $>10.0 \mathrm{mmol} / \mathrm{L}$ (Table 2).

We further analyzed the PGE of each patient. As shown in Table 3, the pre-meal glucose level and postprandial peak glucose level for each meal after postprandial Prandilin 25 injection were all similar to those observed following preprandial Prandilin 25 injection. The postmeal peak height and the average time to peak for breakfast, lunch, and dinner were also similar in both groups. No significant differences between the preprandial administration group and the postprandial administration group could be found in the AUCpp values at 1-4 $\mathrm{h}$ after breakfast, lunch, and dinner.

The average glucose concentration measured at a particular time point during a 24 -h period in which Prandilin 25 was administered was similar regardless of whether the Prandilin 25 was administered preprandially or postprandially (Fig. 1).

\section{Hypoglycemic Episodes}

There were no severe hypoglycemic episodes during the study. The incidence of hypoglycemic episodes after postprandial injection of Prandilin 25 (15 episodes) was similar to that of episodes after preprandial injection (13 episodes) $\left(\chi^{2}=0.170, P=0.681\right)$. Overall, postprandial administration of Prandilin 25 did not increase the incidence of hypoglycemic episodes as compared to preprandial Prandilin 25 administration. Also, the AUC and the percentage of time that the blood glucose level was $<3.9 \mathrm{mmol} / \mathrm{L}$ as detected via CGM did not differ significantly between the two groups (Table 2).

\section{DISCUSSION}

The present study demonstrates that postprandial Prandilin 25 administration has a similar efficacy in clinical practice to preprandial Prandilin 25 administration, not only in terms of reducing hyperglycemia but also in relation to controlling GV and managing hypoglycemic episodes, based on different parameters calculated from the CGM data.

Euglycemic control is essential for preventing acute and chronic diabetic complications in patients with diabetes mellitus. Insulin is considered to be the most effective glucose-lowering agent, and insulin replacement or supplement therapy is a key component of effective diabetes management [1, 11]. However, insulin nonadherence is a very common 
Table 2 The effects of preprandial injection and postprandial injection with metformin on GV

\begin{tabular}{llll}
\hline Treatment & Preprandial & Postprandial & P value \\
\hline 24hMAGE $(\mathrm{mmol} / \mathrm{L})$ & $4.02 \pm 1.84$ & $4.16 \pm 1.97$ & 0.412 \\
24hSDBG $(\mathrm{mmol} / \mathrm{L})$ & $1.71 \pm 0.71$ & $1.71 \pm 0.81$ & 0.838 \\
LAGE $(\mathrm{mmol} / \mathrm{L})$ & $7.56 \pm 2.93$ & $7.65 \pm 3.50$ & 0.707 \\
$24 \mathrm{hMBG}(\mathrm{mmol} / \mathrm{L})$ & $7.34 \pm 1.08$ & $7.21 \pm 1.00$ & 0.183 \\
AUC $<3.9$ & $0.00(0.00,1.00)$ & $0.00(0.00,0.00)$ & 0.266 \\
$<3.9$ time $(\%)$ & $0.00(0.00,0.34)$ & $0.00(0.00,0.35)$ & 0.481 \\
AUC $>10$ & $99.75(0.00,483.37)$ & $87.05(0.00,409.87)$ & 0.936 \\
$>10$ time $(\%)$ & $7.29(0.00,16.84)$ & $7.29(0.00,14.24)$ & 0.188 \\
\hline
\end{tabular}

$M B G$ mean blood glucose concentration (mmol/L), $S D B G$ standard deviation of the MBG $(\mathrm{mmol} / \mathrm{L}), M A G E$ mean amplitude of glycemic excursion (mmol/L), $L A G E$ large amplitude of glycemic excursion, $A U C<3.9$ the decremental area above the curve for blood glucose concentrations below $3.9 \mathrm{mmol} / \mathrm{L}(\mathrm{mmol} / \mathrm{L} \mathrm{min}),<3.9$ time the percentage of time that the blood glucose concentration was below $3.9 \mathrm{mmol} / \mathrm{L}, A U C>10$ the incremental area under the curve for blood glucose concentrations above $10.0 \mathrm{mmol} / \mathrm{L}(\mathrm{mmol} / \mathrm{L} \mathrm{min}),>10$ time the percentage of time that the blood glucose concentration was above $10.0 \mathrm{mmol} / \mathrm{L}$

phenomenon that leads to suboptimal glycemic control in the clinical setting $[5,7]$. Injection time inflexibility is an important factor that contributes to insulin nonadherence [6]. On the other hand, there are many social situations (parties, dinners) in which the preprandial insulin dose cannot be precisely estimated in advance. The present study indicates that a postprandial insulin dose might be an alternative or compensational option for patients who forget their routine preprandial injection.

One of the main differences between our study and previous clinical trials [16-18] was that we set the MII to $30 \mathrm{~min}$, not $15-20 \mathrm{~min}$. Although we extended the MII to $30 \mathrm{~min}$, our data demonstrated that the efficacy of postprandial insulin lispro 25 administration is not inferior in clinical practice to preprandial insulin lispro 25 administration. Based on this and previous studies [12-14], we can conclude that injecting insulin lispro 25 within $30 \mathrm{~min}$ after meal onset is a reasonable and feasible approach to achieve glycemic control in T2DM patients. Extending the MII to 30 min could theoretically provide patients undergoing insulin lispro 25 treatment with more time flexibility, which may then result in improved insulin adherence.
Another important difference between our study and previous clinical trials was that we used CGM to evaluate the daily GV and PGE values of enrolled patients. CGM can be used to check the subcutaneous interstitial fluid glucose level automatically every $5 \mathrm{~min}$, thus comprehensively and accurately highlighting blood glucose excursions throughout the day [20]. Our study demonstrated that both postprandial administration and preprandial administration had similar efficacies for the management of hyperglycemia, as evidenced by $24 \mathrm{hMBG}$, premeal BG, and postprandial peak BG for each meal at the same dose. Moreover, both treatments had a similar effect on GV control (which influences micro- and macrovascular complication development [21, 22]), as shown by various parameters: 24hMAGE, 24hSDBG, LAGE, and AUCs for blood glucose levels below $3.9 \mathrm{mmol} / \mathrm{L}$ and above $10.0 \mathrm{mmol} / \mathrm{L}$ (Table 2). Furthermore, postprandial injection did not change the percentages of time that the blood glucose level was below $3.9 \mathrm{mmol} / \mathrm{L}$ or above $10.0 \mathrm{mmol} / \mathrm{L}$ as compared to preprandial injection (Table 2). In terms of postprandial hyperglycemia, which is an independent risk factor for cardiovascular disease [23] and oxidative stress [24], the peak heights and the AUCpp values 1-4 h after 
Table 3 The effect of pre- and postprandial injection with metformin on postprandial glucose excursions

\begin{tabular}{|c|c|c|c|}
\hline & Preprandial & Postprandial & $P$ value \\
\hline \multicolumn{4}{|l|}{ Breakfast } \\
\hline Premeal (mmol/L) & $7.0871 \pm 1.356$ & $7.040 \pm 1.611$ & 0.818 \\
\hline PPG peak $(\mathrm{mmol} / \mathrm{L})$ & $11.042 \pm 3.032$ & $11.45 \pm 3.11$ & 0.244 \\
\hline Peak height $(\mathrm{mmol} / \mathrm{L})$ & $3.60(2.20,5.45)$ & $3.90(2.20,5.87)$ & 0.288 \\
\hline Time to peak (min) & $89.72 \pm 35.52$ & $85.51 \pm 28.06$ & 0.273 \\
\hline \multicolumn{4}{|c|}{ AUCpp CGM $(\min * \mathrm{mmol} / \mathrm{L})$} \\
\hline $1 \mathrm{~h}$ & $65.50(29.70,99.97)$ & $69.25(34.20,105.70)$ & 0.227 \\
\hline $2 \mathrm{~h}$ & $214.50(108.97,333.55)$ & $250.25(130.75,384.75)$ & 0.160 \\
\hline $3 \mathrm{~h}$ & $350.45(179.83,576.50)$ & $380.00(172.75,611.00)$ & 0.507 \\
\hline $4 \mathrm{~h}$ & $365.82(199.75,683.12)$ & $398.00(176.87,737.10)$ & 0.688 \\
\hline \multicolumn{4}{|l|}{ Lunch } \\
\hline Premeal (mmol/L) & $6.79 \pm 1.90$ & $6.46 \pm 1.72$ & 0.127 \\
\hline PPG peak $(\mathrm{mmol} / \mathrm{L})$ & $8.589 \pm 2.288$ & $8.326 \pm 2.289$ & 0.201 \\
\hline Peak height $(\mathrm{mmol} / \mathrm{L})$ & $1.40(0.60,2.50)$ & $1.46(0.90,2.49)$ & 0.577 \\
\hline Time to peak (min) & $76.37 \pm 34.24$ & $78.68 \pm 26.71$ & 0.579 \\
\hline \multicolumn{4}{|c|}{ AUCpp CGM $(\min * \mathrm{mmol} / \mathrm{L})$} \\
\hline $1 \mathrm{~h}$ & $23.25(3.33,53.92)$ & $27.75(3.62,54.72)$ & 0.245 \\
\hline $2 \mathrm{~h}$ & $60.15(21.62,144.56)$ & $85.25(34.37,154.25)$ & 0.221 \\
\hline $3 \mathrm{~h}$ & $90.50(25.83,263.50)$ & $126.25(62.32,268.57)$ & 0.201 \\
\hline $4 \mathrm{~h}$ & $124.10(28.56,339.82)$ & $165.50(71.70,398.65)$ & 0.323 \\
\hline \multicolumn{4}{|l|}{ Dinner } \\
\hline Premeal (mmol/L) & $6.92 \pm 1.70$ & $6.86 \pm 1.81$ & 0.811 \\
\hline PPG peak $(\mathrm{mmol} / \mathrm{L})$ & $9.30 \pm 2.36$ & $9.38 \pm 2.31$ & 0.765 \\
\hline Peak height $(\mathrm{mmol} / \mathrm{L})$ & $2.40(1.00,3.30)$ & $2.20(1.20,3.45)$ & 0.361 \\
\hline Time to peak (min) & $72.49 \pm 32.52$ & $72.43 \pm 29.85$ & 0.987 \\
\hline \multicolumn{4}{|c|}{ AUCpp CGM $\left(\min ^{*} \mathrm{mmol} / \mathrm{L}\right)$} \\
\hline $1 \mathrm{~h}$ & $37.00(16.62,77.50)$ & $39.50(20.90,75.45)$ & 0.866 \\
\hline $2 \mathrm{~h}$ & $122.25(33.75,204.45)$ & $104.95(47.15,176.37)$ & 0.698 \\
\hline $3 \mathrm{~h}$ & $171.00(60.80,303.75)$ & $151.50(55.91,273.77)$ & 0.401 \\
\hline $4 \mathrm{~h}$ & $198.00(83.62,375.90)$ & $163.50(62.75,327.37)$ & 0.329 \\
\hline
\end{tabular}

PPG postprandial glucose; peak height, calculated as (PPG peak minus premeal glucose); AUCpp CGM, postmeal relative areas under the continuous glucose monitoring curve 




Fig. 1 Plot of the glucose concentration measured (using a CGMS) each hour over a 24-h period during which Prandilin 25 was administered either preprandially or

breakfast, lunch, and dinner were similar in the two groups, indicating that postprandial injection would not increase the HbA1c level compared to preprandial injection over the long term.

Hypoglycemia, which is the primary potential complication of antidiabetes medicines, is strongly associated with an increased risk of cardiovascular events and death [25]. The timing of Prandilin 25 administration did not appear to affect the rate of hypoglycemia. The patients did not have severe hypoglycemic episodes during the study. Using CGMS, we were able to identify asymptomatic or nocturnal hypoglycemia. Our data showed that the frequency of hypoglycemic episodes (blood glucose $<3.9 \mathrm{mmol} / \mathrm{L}$ ) was similar in both treatments. Therefore, postprandial Prandilin 25 administration did not significantly increase the risk of hypoglycemia. postprandially. Data are mean \pm SD values. Meal times were 07:00, 11:00, and 17:00 for breakfast, lunch, and dinner, respectively

There were limitations of the present study. First, this was a short-term clinical study. We did not compare long-term postprandial and preprandial administration of Prandilin 25 in terms of efficiency and safety. Second, we did not conduct a randomized crossover trial to completely exclude bias due to endogenous insulin production resultiing from the elimination of glucotoxicity. However, there was only one day between the preprandial injection and postprandial injection treatments. In addition, the present study did not intend to replace routine preprandial injection with postprandial injection in the long term for those patients on a low premix insulin analogue therapy; this study was performed to identify a reasonable MII for T2DM patients who have forgotten to or cannot perform their preprandial injection. 


\section{CONCLUSIONS}

In summary, this clinical trial indicates that postprandial administration (within $30 \mathrm{~min}$ after meal onset) of Prandilin 25 may be an appropriate alternative for T2DM patients to use when they omit their routine preprandial injection.

\section{ACKNOWLEDGEMENTS}

The authors would like to thank the patients for participating in this study.

Funding. The study and article processing charges were supported by the Scientific and Technological Development Program of Jiangsu Province of China (BL2014010 to Jian-hua Ma) and The Nanjing Medical Science Fund for Distinguished Young Scholars (JQX12006 to Jian Zhu).

Authorship. All named authors meet the International Committee of Medical Journal Editors (ICMJE) criteria for authorship for this manuscript, take responsibility for the integrity of the work as a whole, and gave final approval for the version to be published.

Authorship Contributions. Jian-hua Ma, Jian Zhu, and Lei Ye contributed to the conception and design of the study. Yong Luo, Wen-ji Ni, BO Ding, Xiang-hong Xu conducted the study and collected data. Yong Luo, Wen-ji $\mathrm{Ni}$, and Jian Zhu contributed to data analysis. Jian Zhu contributed to manuscript writing. Jian Zhu and Jian-hua Ma provided final approval of the manuscript.

Disclosures. The authors (Yong Luo, Wen-ji $\mathrm{Ni}$, BO Ding, Xiang-hong Xu, Lei Ye, Jian-hua $\mathrm{Ma}$, Jian Zhu) have no conflict of interest to declare.

Compliance with Ethics Guidelines. All procedures followed were in accordance with the Helsinki Declaration of 1964, as revised in
2013. Informed consent was obtained from all patients for inclusion in the study.

Data Availability. The data sets generated and/or analyzed during the current study are not publicly available but are available from the corresponding author on reasonable request.

Open Access. This article is distributed under the terms of the Creative Commons Attribution-NonCommercial 4.0 International License (http://creativecommons.org/licenses/ by-nc/4.0/), which permits any noncommercial use, distribution, and reproduction in any medium, provided you give appropriate credit to the original author(s) and the source, provide a link to the Creative Commons license, and indicate if changes were made.

\section{REFERENCES}

1. Weng J, Ji L, Jia W, Lu J, Zhou Z, Zou D, et al. Standards of care for type 2 diabetes in China. Diabetes Metab Res Rev. 2016;32:442-58.

2. Bajaj S. RSSDI clinical practice recommendations for the management of type 2 diabetes mellitus 2017. Int J Diabetes Dev Ctries. 2018;38:1-115.

3. Mohan V, Kalra S, Kesavadev J, Singh AK, Kumar A, Unnikrishnan AG, et al. Consensus on initiation and intensification of premix insulin in type 2 diabetes management. J Assoc Physicians India. 2017;65:59-73.

4. Osborn CY, Gonzalez JS. Measuring insulin adherence among adults with type 2 diabetes. J Behav Med. 2016;39:633-41.

5. He X, Chen L, Wang $\mathrm{K}, \mathrm{Wu} \mathrm{H}, \mathrm{Wu} \mathrm{J}$. Insulin adherence and persistence among Chinese patients with type 2 diabetes: a retrospective database analysis. Patient Prefer Adherence. 2017;11:237-45.

6. Peyrot M, Barnett AH, Meneghini LF, SchummDraeger PM. Factors associated with injection omission/non-adherence in the Global Attitudes of Patients and Physicians in Insulin Therapy Study. Diabetes Obes Metab. 2012;14:1081-7.

7. Peyrot M, Barnett AH, Meneghini LF, SchummDraeger PM. Insulin adherence behaviours and barriers in the multinational Global Attitudes of Patients and Physicians in Insulin Therapy Study. Diabet Med. 2012;29:682-9. 
8. Garber AJ, Ligthelm R, Christiansen JS, Liebl A. Premixed insulin treatment for type 2 diabetes: analogue or human? Diabetes Obes Metab. 2007;9:630-9.

9. Sheu WH, Ji L, Lee WJ, Jabbar A, Han JH, Lew T. Efficacy and safety of premixed insulin analogs in Asian patients with type 2 diabetes: a systematic review. J Diabetes Investig. 2017;8:518-34.

10. Muller N, Frank T, Kloos C, Lehmann T, Wolf G, Muller UA. Randomized crossover study to examine the necessity of an injection-to-meal interval in patients with type 2 diabetes and human insulin. Diabetes Care. 2013;36:1865-9.

11. Davies MJ, D'Alessio DA, Fradkin J, Kernan WN, Mathieu C, Mingrone G, et al. Management of hyperglycemia in type 2 diabetes, 2018. A consensus report by the American Diabetes Association (ADA) and the European Association for the Study of Diabetes (EASD). Diabetes Care. 2018;41(12):2669-701.

12. Galic E, Vrtovec M, Bozikov V, Schwarzenhofer M, Milicevic Z. The impact of the timing of Humalog Mix25 injections on blood glucose fluctuations in the postprandial period in elderly patients with type 2 diabetes. Med Sci Monit. 2005;11:87-92.

13. Herz M, Sun B, Milicevic Z, Erickson P, Fovenyi J, Grzywa $M$, et al. Comparative efficacy of preprandial or postprandial Humalog Mix75/25 versus glyburide in patients 60 to 80 years of age with type 2 diabetes mellitus. Clin Ther. 2002;24:73-86.

14. Warren ML, Conway MJ, Klaff LJ, Rosenstock J, Allen E. Postprandial versus preprandial dosing of biphasic insulin aspart in elderly type 2 diabetes patients. Diabetes Res Clin Pract. 2004;66:23-9.

15. Strojek K, Psurek A, Górska J, Szymborska-Kajanek A, Wróbel M, Grzeszczak W. The timing of injection of premixed insulin 30/70 and glucose profile in patients with type 2 diabetes mellitus. Diabet Dośw Klin. 2009;9:12-6.

16. Jacobsen LV, Sogaard B, Riis A. Pharmacokinetics and pharmacodynamics of a premixed formulation of soluble and protamine-retarded insulin aspart. Eur J Clin Pharmacol. 2000;56:399-403.

17. Weyer C, Heise T, Heinemann L. Insulin aspart in a 30/70 premixed formulation. Pharmacodynamic properties of a rapid-acting insulin analog in stable mixture. Diabetes Care. 1997;20:1612-4.

18. Luo Y, Wang XQ, Ni WJ, Ding B, Xu XH, Ye L, et al. Comparison of efficacy and economic value of Prandilin 25 and Humalog Mix 25 in patients with newly diagnosed type 2 diabetes by a continuous glucose monitoring system. Diabetes Ther. 2018;9:2219-28.

19. Cichosz SL, Fleischer J, Hoeyem P, Laugesen E, Poulsen PL, Christiansen JS, et al. Assessment of postprandial glucose excursions throughout the day in newly diagnosed type 2 diabetes. Diabetes Technol Ther. 2013;15:78-83.

20. Petrie JR, Peters AL, Bergenstal RM, Holl RW, Fleming GA, Heinemann L. Improving the clinical value and utility of CGM systems: issues and recommendations: a joint statement of the European Association for the Study of Diabetes and the American Diabetes Association Diabetes Technology Working Group. Diabetologia. 2017;60:2319-28.

21. Ceriello A, Ihnat MA. 'Glycaemic variability': a new therapeutic challenge in diabetes and the critical care setting. Diabet Med. 2010;27:862-7.

22. Di Flaviani A, Picconi F, Di Stefano P, Giordani I, Malandrucco I, Maggio P, et al. Impact of glycemic and blood pressure variability on surrogate measures of cardiovascular outcomes in type 2 diabetic patients. Diabetes Care. 2011;34:1605-9.

23. Low Wang CC, Hess CN, Hiatt WR, Goldfine AB. Clinical update: cardiovascular disease in diabetes mellitus: atherosclerotic cardiovascular disease and heart failure in type 2 diabetes mellitus-mechanisms, management, and clinical considerations. Circulation. 2016;133:2459-502.

24. Wright E Jr, Scism-Bacon JL, Glass LC. Oxidative stress in type 2 diabetes: the role of fasting and postprandial glycaemia. Int $\mathrm{J}$ Clin Pract. 2006;60:308-14.

25. Seaquist ER, Anderson J, Childs B, Cryer P, DagogoJack S, Fish L, et al. Hypoglycemia and diabetes: a report of a workgroup of the American Diabetes Association and the Endocrine Society. Diabetes Care. 2013;36:1384-95. 